\title{
The Research of Current Situation Investigations and Countermeasures of the Golf Tourism in Yunnan Province
}

\author{
Guo Zhifeng ${ }^{1}$ \\ Department of physical education in Kunming university \\ of science and technology \\ Kunming,China \\ 471563075@qq.com
}

\begin{abstract}
By using literature, questionnaire, mathematical statistics methods, the current situation of Yunnan golf tourism is investigated, and the relevant countermeasures and suggestions are put forward.
\end{abstract}

Keywords-countermeasures; current situation; Yunnan; golf tourism

\section{I.INTRODUCTIONS}

Golf tourism is a golf tour service for golf lovers or golf tourists which is specially planned and operated by the professional travel agencies. In this trip, golf enthusiasts or tourists will travel to other cities or foreign golf courses for something tourism and leisure activities such as playing golf, business meeting, taking a leisurely life, visiting or shopping in the local malls can be referred to as the golf tourism. In this paper, four famous golf clubs in yunnan province are investigated and researched on the current situation of golf tourism in order to find advantages and problems of golf tourism in yunnan and put forward the corresponding development countermeasure. With those firm basis, we can promote healthy development of golf tourism and the second entrepreneurship in yunnan, as well as the shifts of the tourism development direction to sightseeing, relaxation, and vocation.

\section{RESEARCH METHODS}

\section{A. Questionnaire survey method}

Selecting four of the biggest clubs in yunnan province: Wanda sunshine golf club, Dianchi golf club, Sunshine golf club and hot spring golf club, the questionnaire survey is conducted for their four clubs visitors and members. Questionnaire reliability and validity are tested, 120 from the total 130 are tested as the effective questionnaires, and the effective recovery rate was $92.3 \%$.

\section{$B$ Documents survey method}

Mainly consult journals and essays related to the golf tourism from internet

\section{Mathematical statistics method}

The data from questionnaire is counted and processed by spss18.0.

\author{
Zhang Lin $^{2}$ \\ Yunnan open university \\ Kunming,China \\ 751271738@qq.com
}

\section{THE CURRENT SITUATION INVESTIGATION AND ANALYSIS OF GOLF TOURISM IN YUNNAN PROVINCE}

\section{A Basic information and analysis of the respondents}

There are 120 respondents in the above four golf clubs, male 86 and female 34 , the ratio between male to female is close to $7: 3$. All the respondents in ages from 30 to 50 account for $64.2 \%$, those ages from 20 to 30and those over 50 account for $15.8 \%$ and $14.2 \%$ respectively, those ages above 20 account for $5.8 \%$. Thus the main golf tourists in yunnan are those middle-aged, men especially.

About the respondents' degrees, those owning college or bachelor degree account for $58.3 \%$, those owning master or above degrees account for $22.5 \%$. In the annual income aspect, ones whose income is below 100,000 yuan and ones whose income is during 100,000 to 300,00 yuan are $9.2 \%$ and $12.5 \%$ of the total respectively. The numbers of those who have 300 thousand to 500 thousand and those who have 500 thousand to 1 hundred, or those who have 1hundred to 5 hundred account for $24.2 \%, 27.5 \%$ and $27.5 \%$, respectively. Even those people whose annual income is above 5 hundred account for $6.7 \%$ of the total. About their engagements, "business", "real estate", "financial industry" and "other industries" accounted for 13.3\%, 13.3\%, 14.2\% and 20\%, respectively; "business unit", "government agency", "telecommunications or IT", "media or cultural industry " are less than $10 \%$. Therefore, customers basically belong to the people of high income. Their professionals are very extensive and their educated degree is high, but the numbers of people who engages in the traditional professionals (e.g., institutions, government agencies) are not very high.

$B$ The current situation and analysis of the respondents in yunnan golf tourists

I)Travel frequency, duration and seasons options and analysis

The respondents numbers who travel to yunnan for golf tourism per year account for 16.7\%, "2-3 times" account for $41.7 \%$, "4 times and above" account for $40.8 \%$. From this we can learn that yunnan golf tourism is attractive to visitors, and tourists golf travel frequencies are high. In one tour, the numbers of the duration of "2 days" account for 5\%, "3-4 days" 34.2\%, "more than 5 days" $18.3 \%$, and "uncertain" $42.5 \%$. By data we can see 
that numbers of tourists whose duration is "3 days or more" account for more than half, and nearly forty percent of tourists' golf tourism duration are fluid. In the choices of the tourism season, 66.7\% are "not sure", which may be associated with kunming's four spring-like climate, coupled with its regional diversity, all of which make it possible to play golf any time throughout the year.

\section{II)Consumption, destination options and analysis}

On respondents' main consumptions, $70.8 \%$ is "golf course consumption", 25.8\% is "tourism consumption", $3.4 \%$ is "shopping consumption", which proves that golf course consumption is the main. In the choices of yunnan golf tourism destinations, 69.2\%" are "kunming", 10\% and $20.8 \%$ are "Dali" and "lijiang" respectively. So kunming is the most favorite partly because of its convenient traffic, urban development degree in advantages and good qualities in golf courses. In the choices of traveling cities, "one city" (48.3\%), "two cities" (29.2\%), "three and above (22.5\%), which show that golf courses and the great tourism resources are attractive to them.

\section{III)Tourism motives and analysis}

Among the main reason for the golf tourism in yunnan, $55.8 \%$ and $48.3 \%$ respectively choose "climate" and "field", $20.8 \%$ and $19.2 \%$ choose "other tourism resources" and "service level". This proves that tourists attach more importance to the unique climatic conditions and high quality courses.

In the choise on "The purpose of the golf tourism in yunnan province", "leisure", "meet friends with golf ", "experience", "have a special liking for golf tourism" are $36.7 \%, 40.0 \%$, 31.7\% and $40.0 \%$, respectively. Therefore the unique charm of golf, together with high quality tourist resources in yunnan province deeply attract tourists from different areas. The "business need" (37.5\%) also illustrates fact that golf has become a important way of social communications.

IV)Golf course attention degree and analysis

The paper conducts 5 aspects, and their orders from the most attached to the least are"quality", "popularity", "service level", "price", "distance". The standard deviation of "quality" is the minimum, so visitors generally consider the course quality the most widespread. The mean value of "distance" is the maximal and standard deviation is the minimum, which proves that areas of the course is not important in tourists, they in truth attach more importance to the playing participation and experiencing process. The standard deviation of "price" is the most biggest, which proves it will cause different influences to different tourists.

\section{b) Golf toursim attention degree and analysis}

The paper conducts 5 aspects, and their orders from the most attached to the least are"play golf", "service", "accommodation", "appreciate local customs", "shopping". In all respects tourists attach most importance to playing golf and the related service, then the shopping or other leisure activities. Through the data analysis, the standard deviation and variance of "service" and "accommodation" are the smallest, which proves that visitors identifies mostly in these two indexes. The discrete degree among "Shopping", "play golf" and "appreciate local customs" are bigger, which reflects tourists' opinions are different in these two indexes greatly. Parts of tourists only aim to play golf or relationships, doing businesses, others may go shopping or do something leisurely mainly.

$72.5 \%$ of visitors will choose play golf together with travelling in yunnan if they have time. The reasons of their wouldn't stay is that: $64.2 \%$ of the tourists are "having no time", "the tourism events aren't attractive", "having no interests", "for other reasons" are 15.8\%, $13.3 \%$ and $13.3 \%$ respectively. This show that most of the tourists have the intension of traveling except for playing golf. However, some reasons like tourists personal factors, the combining disadvantages between the golf and the tourisms.

\section{CONCLUSIONS}

The tourists of golf tourism in yunnan still are the high income people. Golf courses of high qualities and a variety of tourism resources brought by the unique climate and geographical diversity attract people most. Now tourists' consumptions on golf is its course consumption, then the leisure activities consumptions. Although there are different influences in the facets between tourists intensions and the playing prices, most of the tourists attach most importance to the superior quality golf courses, the services related to the golf playing, golf playing itself as well as the experience process. The organizational form of golf tourism in yunnan is diversified, however, tourists organizing is the most common way. At present, the golf tourism in yunnan still needs to improve the relevant organizations' service level and to further expand and develop its tourist resources' superiority, and the golf and tourism resources should be integrated to promote industries' healthy and long-term development.

\section{V.SUGGESTIONS AND COUNTERMEASURES}

\section{A. Strengthen the golf education and train professionals of high qualities}

We can use television, radio, newspapers, network and so on to propaganda by media, advertise yunnan's unique golf tourism brand. Golf enterprises should take an active part in all kinds of travel fairs, such as fair opportunities to fully show the high-end tourism resources in yunnan and its image. To fully develop the self-organization of the golf, set up a variety of communities and make the folk organization develop healthily. Consider to construct the golf public courses, gradually making golf into the national fitness activities. To carry out multi-levels golf games, not only with competitions of high levels, but also with some affordable golf enthusiasts' competitions which will attract more and more public attentions. 
B. Intensify the extent of the development of golf tourism products, promote the advantages combining between the golf and the tourism resources, improve the service abilities and its level

On the one hand, according to different demands the golf courses of location design and characteristics should be constructed. On the basis of recreation and tourism, we should combine golf with urban cultural tourism, ecological tourism, business travel, leisure and special tourism, strengthen the match between the scenic spot shapes and golf course design qualities, gradually form a regional golf tourist destinations combined with function of business center, cultural exchanges and tourism distribution center and so on to build yunnan brand. On the other hand, we should continuously improve service qualities to make golf tourists feel at ease and enjoy services of superior qualities.

channels cultivate and train the talents as soon as possible and improve the comprehensive qualities of the existing staffs. In addition, the introduction of cultivating professional talents of golf at home and abroad to the club, which will lay the solid foundation for the development of golf for their advanced experiences in the management system. At the same time the development to golf youngsters should be cared for and the schools should provide students

C Through various channels to broaden the golf tourism organization forms

Mobilize and exert the positive roles of all kinds of golf club organizations to set up a special market and professional operating mechanism; dig unique and suitable route to meet the special requirements of golf tourism; promote the local golf brand influences to attract more and more friends taking part in the golf event; make the golf tourism develop on a regular circle and improve its competitive abilities.

\section{REFERENCES}

[1] Wang feijia.Research on current situation of management of golf tourism market in China[J]. Journal of Guangzhou sport university, 2008(5)

[2] Xing ling, Deng yi. The suggestions and countermeasures of promoting actively the development ot golf tourism in yunnan[J]. Science and technology management in Yunnan, 2008

[3] Li zichao.Golf tourism research present situation probing[J]. Special zone economy,2009

[4] Li zichao. Research on Beijing Golf Tourism Cognition and Related Measures[D]. Beijing forestry university, 2009

[5] Zhou huating. Review of golf tourism theory research in China[J]. Journal of tianjin university of commerce, 2012(3) 